\title{
BIOSSEGURANÇA EM UMA UNIDADE DE TERAPIA INTENSIVA - A PERCEPÇÃO DA EQUIPE DE ENFERMAGEM
}

\author{
Biosecurity in an Intensive Care Unit - \\ the Nursing Team Perception \\ Bioseguridad en una Unidad de Terapia Intensiva - \\ la Percepción del Equipo de Enfermería
}

\begin{abstract}
Resumo
0 estudo, de cunho descritivo com abordagem qualitativa, teve como objetivos: descrever as medidas de biossegurança adotadas pela equipe de enfermagem durante a assistência prestada em UTI; identificar a percepção da equipe de enfermagem acerca da importância da adoção e implementação de medidas de biossegurança durante esta assistência e analisar as possibilidades de implementação por esta equipe de medidas de biossegurança durante esta assistência. Os dados foram obtidos por meio de observação sistemática e entrevistas com roteiro semi-estruturado, realizadas na UTI onde trabalhavam 29 profissionais de enfermagem.A análise temática das entrevistas permitiu identificar três categorias: medidas de biossegurança adotadas pela equipe de enfermagem; percepção desta equipe em relação à importância da adoção e implementação das medidas de biossegurança; e possibilidades de intervenção para a adoção e implementação de medidas de biossegurança.Verificou-se que as normas de biossegurança devem incluir as "boas práticas", possibilitando alcançar um ambiente laboral sem riscos ocupacionais.
\end{abstract}

Palavras-chave: Enfermagem do Trabalho. Biossegurança.

Abstract

The descriptive study having a qualitative approach aimed at: describing the biosecurity measures adopted by the nursing team during the attendance on an ICU identifying the perception of the nursing team about the importance of adopting and implementing biosecurity measures during the attendance and analyzing the possibilities to the team of implementing some biosecurity measures during the attendance. The data were obtained by means of the systematic observation and interviews with semistructured script, carried out on an ICU where 29 nurses used to work. The thematic analysis of the interviews allowed identifying three categories: biosecurity measures adopted by the nurse team; perception of this team concerning the importance of adopting and implementing the biosecurity measures and the possibilities of intervention for the adoption and implementation of the biosecurity measures. It was verified that the biosecurity rules must include the good practices, making possible to reach a labor ambience with no occupational risks.

Keywords: Occupational Health Nursing. Biosecurity.

\section{Resumen}

El estudio es de cuño descriptivo con abordaje cualitativo, tuvo como objetivos: describir las medidas de bioseguridad adoptadas por el equipo de enfermería durante la asistencia prestada en UTI; identificar la percepción del equipo de enfermería acerca de la importancia de la adopción e implementación de medidas de bioseguridad durante esta asistencia y analizar las posibilidades de implementación por este equipo de medidas de bioseguridad durante esta asistencia. Los datos se han obtenido por medio de observación sistemática y entrevistas con guión semiestructurado, realizadas en la UTI donde trabajaban 29 profesionales de enfermería. El análisis temático de las entrevistas permitió identificar tres categorías: medidas de bioseguridad adoptadas por el equipo de enfermería; la percepción de este equipo en relación con la importancia de adoptar e implementar las medidas de bioseguridad y posibilidades de intervención para la adopción e implementación de medidas de bioseguridad. Se ha verificado que las normas de bioseguridad deben incluir las buenas prácticas, posibilitando alcanzar un ambiente laboral sin riesgos ocupacionales.

Palabras clave: Enfermería del Trabajo. Bioseguranza. 


\section{CONSIDERAÇÕES INICIAIS}

0 resultado de um estudo realizado no período de janeiro de 2000 a janeiro de 2001, que teve como sujeitos 68 profissionais de enfermagem de uma Unidade de Terapia Intensiva (UTI) de um hospital universitário em São Paulo, sendo 30 enfermeiros, 13 técnicos de enfermagem e 25 auxiliares de enfermagem, evidenciou que a maioria dos acidentes ocorreu pelo manuseio inadequado de material perfurocortante $(40 \%)$, atingindo os profissionais de enfermagem durante a realização de procedimentos à beira do leito, sendo $10 \%$ quando realizavam aspiração do tubo orotraqueal envolvendo espirro de secreção em pele e mucosa, e outros $10 \%$ ao desprezarem excreta/secreção, que também atingiu os profissionais nas mucosas da face, boca olhos. Foi evidenciado também que $47 \%$ dos acidentes ocorridos estavam relacionados ao contato direto com o cliente e $53 \%$ ao contato indireto. No que diz respeito à utilização dos equipamentos de proteção individual (EPIs) no momento do acidente, $40 \%$ dos profissionais referiram fazer uso dos mesmos e $60 \%$ informaram o contrário ${ }^{1}$.

0 incorreto manuseio de materiais perfurocortantes, 0 contato com secreções e fluidos corporais dos clientes internados e/ou portadores de tuberculose e de microorganismos como Acinetobacter, Methicillin Resistant Staphylococcus Aureus (MRSA), Klebsiella, dentre outros, contribui de forma relevante para o agravamento deste quadro. A questão dos problemas de saúde que afetam os profissionais de enfermagem no ambiente hospitalar está diretamente relacionada aos riscos ocupacionais aos quais estão submetidos cotidianamente, incorrendo em acidentes de trabalho e doenças ocupacionais. Vale lembrar que doença ocupacional é aquela produzida ou desencadeada pelo exercício profissional peculiar a determinada atividade. No caso dos membros da equipe de enfermagem, a doença ocupacional está relacionada aos riscos a que estão submetidos e às suas condições de trabalho, que podem ocasionar acidentes ou resultar em problemas de saúde para seus integrantes².

As doenças ocupacionais e os acidentes de trabalho constituem-se em importantes questões de saúde pública que ainda precisam ser mais bem discutidas, porque os acidentes de trabalho são os agravos mais documentados em relação à saúde do trabalhador, mesmo sabendo-se ainda que existem profissionais de saúde que não os notificam² .

Dependendo da gravidade, além da própria lesão corporal ou perturbação funcional, os acidentes podem causar perda ou redução permanente ou temporária da capacidade para 0 exercício da profissão. Na prática, nem todos os profissionais de enfermagem que atuam em ambientes semicríticos ou críticos, como as UTIs, adotam as medidas de biossegurança necessárias à sua proteção durante a assistência que realizam, o que pode ocasionar agravos à sua saúde e à do cliente sob seus cuidados.

Por estes motivos e de acordo com o que dispõe a Lei ${ }^{\circ}$ 6.367 de 19 de outubro de 1976, é necessário ressaltar a relevância da atenção que deve ser dada às questões de biossegurança no âmbito hospitalar, em especial em UTI, a fim de reduzir o risco de o trabalhador adquirir alguma patologia $\mathrm{e}$ a sua exposição aos acidentes de trabalho, durante a prestação da assistência de enfermagem.

Diante desta realidade, elegemos como objeto deste estudo a percepção da equipe de enfermagem acerca da importância de adotar e implementar medidas de biossegurança em uma unidade de terapia intensiva, como questão norteadora: "como se dá a incorporação das medidas de biossegurança pela equipe de enfermagem em sua prática na UTI? e como objetivos: descrever as medidas de biossegurança adotadas pela equipe de enfermagem durante a assistência prestada em UTI; identificar a percepção da equipe de enfermagem acerca da importância da adoção e implementação de medidas de biossegurança durante a assistência prestada em UTI e analisar as possibilidades de implementação pela equipe de enfermagem de medidas de biossegurança durante a assistência prestada em UTI.

\section{METODOLOGIA DO ESTUDO}

Esta pesquisa foi do tipo exploratória, descritiva, com abordagem qualitativa. 0 estudo foi realizado na Unidade de Terapia Intensiva para adultos de uma instituição de saúde da rede privada do município do Rio de Janeiro onde atuavam, à época, 44 profissionais de enfermagem.

Após solicitação formal junto à referida instituição para realizar o estudo, mediante apresentação de cópias do projeto de pesquisa à Direção e à Gerência de Enfermagem, aprovados por ambos, obteve-se a autorização para dar início ao trabalho, considerando a necessidade de observar o cronograma da pesquisa.

Os sujeitos do estudo foram 29 profissionais de enfermagem, sendo 7 enfermeiros e 22 técnicos de enfermagem, do total de 44 profissionais lotados na UTI. A seleção destes observou o critério de inclusão estabelecido para a pesquisa, qual seja, o tempo de atuação de, no mínimo, seis meses na Unidade, considerando-se que, após este período, já deviam estar familiarizados com as normas e rotinas da Instituição hospitalar em estudo. Apenas dois enfermeiros e 13 técnicos de enfermagem não atenderam a este critério. Todos os que participaram da pesquisa receberam um código numérico $\left(E_{1}, E_{2}, \ldots E_{29}\right)$, escolhido pela pesquisadora para atender ao disposto na Resolução 196/96, do Conselho Nacional de Saúde/MS, que garante 0 anonimato dos participantes em pesquisas envolvendo seres humanos. 0 protocolo da pesquisa foi apreciado e aprovado por Comitê de Ética em Pesquisa (CEP).

Após pedir permissão à enfermeira chefe responsável pela UTI, a pesquisadora entrou em contato com os sujeitos selecionados, descrevendo o projeto que pretendia desenvolver, abordando os objetivos do estudo e a metodologia a ser utilizada, deixando claro que as adesões seriam voluntárias.

A primeira fase da coleta de dados deu-se através da realização de entrevistas semi-estruturadas com os 29 sujeitos do estudo, para aplicar as perguntas elaboradas no roteiro. Estas entrevistas ocorreram em uma sala da própria UTI, com 
a autorização da chefia do setor. Os sujeitos acompanharam a pesquisadora àquele local, onde receberam novas explicações sobre o propósito do estudo e responderam às perguntas previstas no roteiro.

As respostas obtidas foram gravadas em fitas magnéticas, após autorização escrita dos depoentes no Termo de Consentimento Livre e Esclarecido (TCLE), e todos foram informados do posterior acesso à transcrição das suas falas, para validá-las quanto ao respectivo conteúdo, e da possibilidade da desistência de participação em qualquer momento da construção desse estudo, sem prejuízo de qualquer tipo ou natureza. Os dados obtidos nesta fase foram analisados de acordo com os conceitos de Bardin ${ }^{3}$.

Outra técnica utilizada para a coleta de dados utilizada foi a observação sistemática das atividades na UTI, com 0 registro em diário de campo dos fatos observados enquanto os sujeitos atuavam. Neste caso, foi realizada no cenário do estudo após as entrevistas, como forma de complementar as informações dos sujeitos do estudo, ou seja, constatar se aplicavam, na prática, aquilo que tinham dito em relação à utilização das medidas de biossegurança. Para tanto, foi utilizado um check-list elaborado pela pesquisadora.

A observação aconteceu entre os dias 11 e 31 do mês de maio de 2005, num total de 72 horas no serviço noturno e 48 horas no serviço diurno, e foi feita da seguinte forma: a pesquisadora permaneceu na UTI durante seis dias alternados, das 19:00 às 07:00 horas no serviço noturno, e quatro dias alternados, das 07:00 às 19:00 horas, no serviço diurno, totalizando 120 horas de acompanhamento das atividades desenvolvidas pelos sujeitos.

Durante a observação participante, teve-se o cuidado de fazer com que os sujeitos não se sentissem vigiados ou tolhidos em suas atividades, a fim de que não alterassem a sua forma de utilização das medidas de biossegurança ao atuarem na UTI. Para tanto, foi enfatizado a cada um que a meta era apenas observar como a equipe de enfermagem se comportava diante da observância de medidas de biossegurança na UTI.

\section{ANÁLISE E DISCUSSÃO DOS DADOS}

\section{Medidas de biossegurança adotadas pela equipe de enfermagem}

A lavagem das mãos é uma medida de biossegurança entendida por muitos como proteção do cliente, mais do que da equipe de enfermagem. Porém, quanto a este aspecto, os sete enfermeiros e os 22 técnicos de enfermagem realizaram esta medida, o que demonstrou que os sujeitos identificaram esta medida como imprescindível à prevenção de infecções. Sem dúvida, é um procedimento de biossegurança que está incorporado na rotina da equipe de enfermagem.

Este procedimento constitui-se num dos atos mais importantes na profilaxia da infecção hospitalar, pois através das mãos dos profissionais de saúde é que são transportados os microorganismos de um cliente para outro, e também para os equipamentos ${ }^{4}$, fato que deve ser levado em consideração, principalmente em uma UTI, pois o intenso manuseio do cliente e o uso de técnicas invasivas para tratá-lo faz com que fique mais susceptível às infecções.

Outra medida adotada foi o uso dos equipamentos de proteção de segurança, como barreiras primárias de contenção, destacando-se os equipamentos de proteção individual (óculos, luvas, máscaras e capotes) destinados a proteger o trabalhador dos riscos aos quais estão sendo submetidos ao realizar certos procedimentos de rotina com o cliente . $^{5}$

A utilização de EPIs é definida como obrigação do trabalhador, que deve utilizar o equipamento apenas com a finalidade a que se destina, responsabilizar-se por sua guarda e conservação e comunicar ao empregador qualquer dano ou alteração que o torne impróprio para o uso ${ }^{6}$.

Em relação ao uso dos equipamentos de proteção individuais, dentre os 22 técnicos de enfermagem, observouse que nenhum utilizou máscara e óculos ao desprezar as excreções do cliente no expurgo; fizeram apenas uso das luvas, sendo que 20 deles não utilizaram os óculos de proteção ao realizar técnicas como a aspiração de vias aéreas superiores, traqueostomia e tubo orotraqueal.

Todavia, em sua totalidade, a equipe de enfermagem valeuse do uso de luvas e capote ao entrar em contato com o cliente em isolamento de contato, o que foi significativo por se tratar de um dos mais tradicionais e antigos procedimentos preventivos na área de saúde aos potencialmente infectantes como sangue, secreções e excreções. Os EPIs devem ter formato anatômico, boa resistência, fornecer conforto e destreza ao usuário, conferindo maleabilidade e flexibilidade. Ao trabalhador cabe observar os seguintes aspectos ao fazer uso desses equipamentos: calçar as luvas com as mãos limpas e secas, sempre colocá-las sobre o punho do capote, não deixando as mangas soltas sobre as luvas; quando apresentar ferimentos nas mãos, protegê-los com curativo, pois o ferimento sem proteção pode ser agravado pelo uso das luvas devido ao atrito provocado com a pele; não abrir portas ou atender telefones utilizando luvas; trocá-las quando entrar em contato com diferentes clientes e, sobretudo, nunca reutilizá-las.

Quanto aos óculos de proteção, este tipo de EPI confere proteção contra respingos de material infectante; utilizado em procedimentos que ofereçam riscos aos olhos, devem ser confortáveis, leves resistentes e maleáveis, construídos de forma a proteger os olhos completamente, porém sem comprometimento do campo visual, assentando-se de forma confortável sobre 0 nariz, além de possuir proteção lateral. 0 trabalhador deve ter cuidados especiais com o manuseio deste tipo de equipamento: ao retirá-lo, não deixar próximo a fontes de contaminação ou calor, limpá-lo ao término de sua utilização e guardá-lo em local adequado com as lentes para cima, protegidos do calor, do impacto e do contato com produtos químicos ou biológicos ${ }^{5}$.

A máscara é um equipamento destinado à proteção da boca e do nariz do profissional ${ }^{7}$, porém determinados cuidados devem ser empregados por ele durante sua utilização; portanto, a máscara não deve ser usada por um longo período de tempo e nem ser tocada sucessivamente, assim como mantida permanentemente em volta do pescoço, pois além de não conferir a proteção contra gotículas e aerossóis, pode transformar-se em um reservatório de microorganismos ${ }^{8}$. 
Em relação ao uso de EPIs (luva, máscara, óculos), ao desprezar as excreções do cliente no expurgo, observou-se que os técnicos de enfermagem não utilizaram a máscara e os óculos, em sua totalidade; só utilizaram as luvas, como de rotina. Sabe-se que o uso desses equipamentos não reduz a zero os riscos aos quais os profissionais estão sendo submetidos, mas reduzem a quantidade de secreção/sangue inoculados em até $75 \%$ e, por conseqüência, o grau de risco de infecção9.

Diante deste quadro, é possível inferir que há necessidade de que a equipe de enfermagem seja mais bem esclarecida sobre a importância do uso destes EPls. Para tanto, o setor de Engenharia de Segurança no Trabalho, juntamente com o Serviço de Saúde do Trabalhador da Instituição, deve valer-se de seus profissionais para implementar ações nesse sentido.

A equipe de enfermagem, em sua totalidade, respeitou 0 ato de desprezar os perfurocortantes no coletor de descarte, trocando-o quando o mesmo já tinha excedido sua capacidade. Cabe ressaltar que estes coletores de descarte existiam no box/quarto individual de cada cliente internado, o que facilitou o descarte da seringa/agulha imediatamente após a administração do medicamento, evitando o reencape e a ocorrência de acidentes com materiais perfurocortantes.

A UTI é um dos setores em que mais ocorrem acidentes com perfurocortantes porque os profissionais de saúde, em sua grande maioria, cuidam e preservam a vida e a saúde dos clientes, mas descuidam-se, muitas vezes, da própria proteção. Além disso, esta ocorrência está associada ao fato de os profissionais se tornarem mais vulneráveis a este tipo de acontecimento em decorrência de algumas características, como a de ser o maior grupo de profissionais de saúde a prestar assistência ininterrupta durante $24 \mathrm{~h} / \mathrm{dia}$, ser responsável pela execução de, aproximadamente, $60 \%$ das ações de saúde e de manter maior contato físico com os clientes ${ }^{10}$.

Os acidentes de trabalho ocorridos nas unidades de terapia intensiva acontecem por se tratar de um ambiente complexo, que apresenta um elevado número de riscos ocupacionais para a equipe de enfermagem, decorrente tanto da assistência prestada diretamente ao cliente, como do manuseio de equipamentos e materiais perfurantes e/ou cortantes, que podem estar contaminados por sangue e outros fluidos corporais, representando a educação permanente da equipe de enfermagem um desafio para a prevenção de acidentes ${ }^{11}$.

Quanto maior for a manipulação dos objetos perfurocortantes, de sangue e de fluidos orgânicos, maior será a exposição do trabalhador a doenças como AIDS e hepatites B e C; portanto, medidas como o não-reencape de agulhas devem ser rigorosamente observadas para minimizar os acidentes ocasionados por esta prática inadequada ${ }^{8}$.

No que diz respeito ao transporte da roupa suja, observouse que os 22 técnicos de enfermagem utilizaram sacos impermeáveis para fazê-lo. Todavia, as medidas de biossegurança não foram observadas completamente, pois apenas foram utilizadas luvas, proteção adotada rotineiramente.

Quanto às roupas de proteção, estas devem ser utilizadas em todas as atividades que possam vir a provocar doenças ocupacionais por contaminação; sendo assim, o uso do capote é indicado para a proteção da pele, devendo ser de manga longa, cobrindo além dos braços, o dorso, as costas e parte das pernas acima dos joelhos, atuando como barreira de proteção também para a roupa do profissional contra a exposição a sangue e a fluidos corpóreos. Todavia, o trabalhador deve adotar alguns cuidados quanto ao uso correto e adequado deste equipamento: o capote deve ser utilizado com a parte aberta voltada para as costas, pois, do contrário, além de não oferecer a proteção adequada, pode ainda provocar acidentes; nunca arregaçar as mangas para não expor a pele ao contato com agentes infecciosos; ao término de sua utilização, retirá-lo, deixando exposta a parte interna para que possa ser usado por outra pessoa, e substitui-lo sempre que estiver sujo ou molhado ${ }^{5}$.

As atitudes dos profissionais observados demonstraram que, na prática assistencial, deixam de dar importância à adoção destas medidas de biossegurança na assistência prestada, 0 que pode colocá-los em risco de adquirir alguma doença ocupacional ou de sofrer um acidente de trabalho.

Os profissionais de enfermagem estão expostos a uma série de riscos durante a execução de seu trabalho, sejam estes físicos, químicos, ergonômicos, psicossociais ou biológicos. Neste caso específico, os sujeitos observados ficaram expostos ao risco biológico, que está relacionado com agentes como sangue e/ou fluidos corpóreos, além daqueles transmitidos por via aérea?

Trata-se de um fato agravante, por ser esta uma equipe que atua em setor específico, destinado ao atendimento de clientes que necessitam de cuidados complexos e especializados, permeado por vários sentimentos e emoções que exigem do profissional preparo para lidar com a perda, a dor e o sofrimento, sem mencionar que a rotina estabelecida exige uma excelente capacitação técnico-científica de cada integrante da equipe. Isto inclui não só que todos saibam identificar as medidas cotidianas de biossegurança que devem ser adotadas durante a assistência de enfermagem, como também percebam que tais medidas são indispensáveis à sua proteção, independente do diagnóstico do cliente internado.

\section{Percepção da equipe de enfermagem em relação à importância da adoção e implementação das medidas de biossegurança}

Em relação à importância da adoção e implementação das medidas de biossegurança, alguns entrevistados tiveram uma percepção correta acerca do assunto, como ficou evidenciado em suas falas: (...) ter um cuidado com o paciente e pensar no cuidado que temos que ter conosco, com o profissional de enfermagem (...) $\left(\mathrm{E}_{2}\right) ;(.$.$) é a segurança tanto do profissional$ quanto do paciente $\left(\mathrm{E}_{6}\right)$.

Durante estudos realizados em hospitais gerais da Bahia, foram encontrados resultados evidentes de que os profissionais de saúde entendem que as medidas de biossegurança devem ser adotadas e utilizadas como precaução e proteção à própria saúde, à de seus colegas e à do cliente sob seus cuidados ${ }^{12}$.

Todavia, $E_{1}$ alertou para o fato de que "(...) poucos são os que sabem (...) o que fazer em caso de acidente com perfurocortante (...)", ressaltando que "(...) a gente conhece no dia-a-dia mesmo (...)", referindo-se às medidas de 
biossegurança. Já $E_{28}$ afirmou que a sua percepção sobre tais medidas é decorrente do que "(...) aprendeu na formação (...)", acrescido daquilo que "....) a gente aprende quando entra dentro da Unidade, através de treinamentos (...)", de onde se pode inferir que a percepção de ambos pautou-se na valorização da experiência profissional cotidiana que tiveram sobre 0 assunto.

Outros dois participantes do estudo reconheceram que sua percepção acerca do assunto não era suficientemente abrangente. Em seus depoimentos, bastante similares, disseram: (...) sobre biossegurança, eu acho que é um tanto restrito (..) $\left(\mathrm{E}_{15}\right) ;(\ldots)$ a respeito de medidas de biossegurança, é um tanto restrito (...) $\left(\mathrm{E}_{25}\right)$.

A equipe de enfermagem descreveu que uma das medidas de biossegurança mais importantes é o uso dos EPIs, relacionando-os com o tipo de procedimento que será realizado no cliente internado, demonstrando, assim, uma preocupação em como utilizá-los e manuseá-los corretamente, considerando que "(...) cada um tem uma finalidade (...)" $\left(\mathrm{E}_{11}\right)$ e que "(...) existem várias medidas de biossegurança; uma delas é o uso dos EPIs (...)" $\left(\mathrm{E}_{22}\right)$.

Quando utilizados adequadamente, os EPIs servem de aliados dos profissionais, livrando-os dos riscos possíveis relacionados ao tipo de atividade que estão executando ${ }^{13}$. Nesse sentido, os entrevistados têm plena consciência da necessidade do uso dos EPIs durante a realização dos cuidados prestados ao cliente no cotidiano da UTI. Especificamente em relação às luvas, eis o que disseram: (...) luvas, para evitar muitas vezes tanto a contaminação do cliente como a nossa contaminação (...) $\left(\mathrm{E}_{22}\right) ;(\ldots)$ luva todo mundo usa (...) $\left(\mathrm{E}_{29}\right)$

As falas anteriores confirmam a observação sistemática realizada, quando se constatou que o $\mathrm{EPI}$ mais utilizado pela equipe de enfermagem foram as luvas, em situações como a do atendimento ao cliente internado na Unidade naquele momento, ou ao se aproximarem para prestar cuidados de enfermagem, como o banho no leito ou a mudança de decúbito.

No caso da máscara, contradizendo as falas de alguns entrevistados, foi possível observar que foi mais usada em situações que exigiram a proximidade ao cliente, no momento de realizar sua higienização por conta de uma evacuação, do que para proteger a face do profissional, ao desprezar as secreções do cliente no expurgo. Dois entrevistados justificaram a necessidade do uso da máscara em certas situações:

(...) com paciente que tenha infecção respiratória, você tem que usar uma máscara apropriada (...) $\left(\mathrm{E}_{16}\right)$

(...) se você for fazer uma aspiração, deve usar máscara

(...) para evitar que algum espirro de secreção venha cair na sua boca ou na sua pele (...) na hora de trocar o selo d'água dos drenos, ou qualquer dreno, você deve utilizar máscara (...). $\left(\mathrm{E}_{17}\right)$

Quanto aos óculos de proteção, a maioria dos entrevistados não observou o seu uso durante a assistência prestada aos clientes, como constatado durante o período em que a pesquisadora esteve presente na UTI realizando a observação sistemática para complementar os dados desta pesquisa. Eis o que três entrevistados disseram a respeito:
(...) os óculos são importantes e quase ninguém usa, principalmente em terapia intensiva (...). $\left(\mathrm{E}_{19}\right)$

(...) é superimportante o uso de óculos de proteção. Acho que apesar da gente ser um pouco arredio a esse uso, principalmente ao dos óculos (...) na correria, a gente acaba não usando e eu acho que é cultural mesmo, a gente não usar (...). $\left(\mathrm{E}_{29}\right)$

Estes relatos confirmam a literatura quanto ao uso, desuso ou uso inadequado dos EPIs ${ }^{13}$. Na teoria, quando entrevistados, todos enfatizaram a importância do uso dos EPIs, porém, o que se observou foi que nem sempre os membros da equipe de enfermagem realmente faziam uso do EPI, ou, quando o faziam, às vezes era de maneira incorreta.

Vale ressaltar que, durante a observação sistemática, ao aspirar o cliente intubado, a maioria dos profissionais não utilizou simultaneamente os óculos de proteção e a máscara, dois equipamentos imprescindíveis à realização da técnica, por prevenir que a secreção do cliente acidentalmente atinja a conjuntiva ou a mucosa do trabalhador.

Este comportamento inadequado dos profissionais de enfermagem, de inobservância às medidas de biossegurança, também foi constatado pela pesquisadora durante o ato de desprezar o conteúdo dos drenos (Jackson, Hemovac), na troca da solução do selo d'água ou ao desprezarem as excreções dos clientes no expurgo.

Em estudos realizados em uma unidade de terapia intensiva, no Espírito Santo, foram encontrados resultados semelhantes no que respeita ao uso inadequado dos EPIs. Porém, o que chamou a atenção foi que a maioria dos profissionais de enfermagem utilizava aqueles equipamentos somente nas situações em que 0 risco estava evidente, como por exemplo, ao prestarem assistência a clientes com HIV ou tuberculose multirresistente, demonstrando que não existia uma conscientização em relação à necessidade da utilização correta dos EPIs durante a execução de procedimentos de enfermagem, mas sim, medo e preconceito de adquirir uma doença ocupacional ${ }^{14}$.

Seis entrevistados fizeram referência ao capote como medida de biossegurança que deve ser adotada na UTI. Durante a observação sistemática, pude constatar que foi o segundo EPI mais utilizado pela equipe de enfermagem, da forma correta e com a preocupação de seus membros em trocá-los quando estavam molhados ou com sujidade, ou a cada 12 horas, como é a rotina pré-estabelecida pela Comissão Interna de Controle de Infecção Hospitalar (CClH) da Instituição.

Esta foi uma constatação importante, pois se este equipamento não for utilizado de maneira correta, torna-se uma fonte de risco de infecção para os clientes que estão sendo assistidos, já que no ato de vesti-lo ou retirá-lo, estando sujo ou molhado, acaba carreando respingos, águas sujas dos banhos realizados, microorganismos transmitidos pelo contato direto com a pele, e isso pode agravar a situação em que estes clientes se encontram. Este aspecto foi observado por um entrevistado, que disse: "(...) no uso do capote, você tem que ter uma técnica para vestir, para tirar esse capote (...)" $\left(\mathrm{E}_{6}\right)$.

A percepção dos profissionais de enfermagem em relação às medidas de segurança e à necessidade de adotá-las 
rotineiramente na UTI foram explicitadas por um dos entrevistados. Segundo ele, as medidas são necessárias porque "(...) a gente tem de estar se cuidando e de estar prevenindo que você se fira, que adquira qualquer patologia ou qualquer outra doença que não seja natural sua (...)" $\left(\mathrm{E}_{8}\right)$.

No que diz respeito ao descarte de material perfurocortante utilizado, deve ser ressaltado que, na unidade de terapia intensiva, cenário deste estudo, após a realização da técnica de administração de medicamentos, os profissionais desprezaram as agulhas e seringas no coletor apropriado, respeitando sua capacidade de armazenamento e trocando-o quando saturado. Este procedimento correto foi justificado da seguinte maneira pelos entrevistados:

(...) evitar acidentes (...) as caixas coletoras de perfurocortantes, que você tem que descartar a agulha sem reencapá-la (...). ( $\left.\mathrm{E}_{16}\right)$

(...) você tem que ter sempre o máximo de cuidado para não reencapar essa agulha. Procurar jogar sempre a seringa com agulha dentro do descarpack. Ter o cuidado de trocar o descarpack quando estiver no seu limite (...) se possível, utilizar pinça para pegar os perfurocortantes e jogar no descarpack (...). $\left(\mathrm{E}_{17}\right)$

As doenças ocupacionais constituem-se em importante problema de saúde pública em todo o mundo, podendo atingir os profissionais de saúde, direta ou indiretamente, durante a assistência prestada ao cliente, o que foi reconhecido por um dos entrevistados ao justificar a adoção e implementação de medidas de biossegurança ${ }^{5}$ :

(...) eu acho que as medidas de biossegurança têm duas finalidades, primeiro de nos prevenir e segundo de não transportar contaminação de um doente para o outro (...) porque a gente vai estar prevenindo a nossa saúde, se protegendo de todos os aspectos e também pra gente não levar contaminação de um paciente para o outro (...) isso é muito fundamental, muito importante pra quem trabalha em hospital. $\left(\mathrm{E}_{11}\right)$

Em geral, a transmissão de agentes biológicos ocorre por inalação, penetração através da pele (parenteral), contato com a pele e mucosas ou ingestã $0^{5}$. As infecções por patógenos de transmissão sangüínea são descritas como as de maior risco para os profissionais de saúde; e as doenças às quais estão expostos com maior freqüência são: AIDS, hepatite B e hepatite C. Entre as infecções transmitidas por via aérea, a tuberculose é a que merece especial atenção, quando comparada a outras doenças como: influenza, varicela, coqueluche e doença meningocócica, pois estudos demonstram que o risco de 0 profissional de enfermagem adquirir tuberculose é oito vezes maior, diante de outros profissionais de saúde, por estarem mais diretamente em contato com os clientes.

Diante do exposto, deve-se destacar a fala de um entrevistado a propósito da importância das medidas de biossegurança:

(...) é importante porque, além de oferecer segurança pra gente em primeiro lugar, oferece segurança pro cliente também. Porque além deles poderem estar transmitindo pra gente algum tipo de patologia, a gente também pode estar transmitindo pra eles algum tipo de patologia ou coisa parecida (...). $\left(\mathrm{E}_{13}\right)$

As medidas profiláticas de pré e pós-exposição destes profissionais, tais como imunizações (contra hepatite $B$, por exemplo) e uso de quimioprofilaxias, associadas à implementação de medidas de biossegurança, podem ser indicadas de acordo com o tipo de exposição e o agente infeccioso envolvido, evitando que adquiram uma doença ocupacional no ambiente hospitalar, o que foi corroborado pelos entrevistados:

(...) as medidas de biossegurança visam prevenir $e$ evitar acidentes relacionados ao trabalho, evitar que 0 profissional se contamine com os dejetos do paciente e com os próprios artigos perfurocortantes ao manuseá$\operatorname{los}(\ldots) .\left(\mathrm{E}_{22}\right)$

(...) acho imprescindível pra gente continuar assistindo o paciente com qualidade porque se a gente não tiver saúde, não tem como. E principalmente pra gente, pra evitar adquirir essas doenças todas que a gente já sabe, como hepatite, $H I V(. .$.$) . \left(\mathrm{E}_{29}\right)$

Durante a realização das entrevistas, foi possível perceber que a maioria dos sujeitos, mesmo tendo recebido treinamento em biossegurança no próprio ambiente de trabalho, não fez uso dos equipamentos de proteção individual durante a assistência de enfermagem; e, ainda, que depois do treinamento inicial, não realizou outro curso nem participou de palestras sobre o tema; ou seja, não buscou atualizar seus conhecimentos a respeito.

Pode-se inferir que a ênfase dada à importância da adoção e implementação das medidas de biossegurança durante a assistência de enfermagem prestada na UTI não se confirma na prática. Ou seja, as medidas são importantes no imaginário dos profissionais que sabem o quanto isso pode contribuir para sua proteção ao cuidar do cliente internado; mas são empreendidas de forma impensada, apenas porque são normas impostas pela Instituição na qual trabalham, fato este que deve ser considerado, pois há que se buscar implementá-las com a participação do profissional, a partir da sua compreensão acerca do risco existente nas diferentes ações da assistência aos clientes.

\section{Possibilidades de intervenção para a adoção e implementação de medidas de biossegurança}

A educação permanente em biossegurança foi uma das possibilidades de intervenção para a adoção e implementação de medidas de biossegurança referidas pelo entrevistado, como se segue: (...) acho que deveria falar mais, tipo palestras, cartazes, falar mais sobre esse tema, pois é muito importante (...) é muito importante a orientação em biossegurança (...). $\left(\mathrm{E}_{7}\right) ;(. .$.$) eu acho que poderia haver uma melhor forma de$ educação continuada $\left(\mathrm{E}_{15}\right)$.

A prevenção nas instituições de saúde é um fenômeno que deve ser analisado coletivamente, pois este está ligado diretamente ao treinamento, ou seja, à educação permanente ${ }^{15}$.

Constata-se uma situação controversa entre os membros da equipe de enfermagem: em seus depoimentos, demonstram ter uma percepção favorável à implementação das medidas de biossegurança, quando na prática, o que se constatou foi 
exatamente o oposto, isto é, todos utilizam rotineiramente apenas duas medidas: a de lavar as mãos e a de usar luvas. Portanto, mudar este quadro desfavorável dependerá somente da implantação da educação permanente.

Outra possibilidade de intervenção para modificar este panorama foi a prevenção, conforme mencionado por três entrevistados: (...) prevenir alguns acidentes com pacientes (...) $\left(\mathrm{E}_{19}\right) ;(. .$.$) prevenir e$ evitar acidentes relacionados ao trabalho $\left(\mathrm{E}_{22}\right)$.

A implementação das 'boas práticas' é fundamental para a prevenção de acidentes de trabalho e de doenças relacionadas ao trabalho. De acordo com a NR-5, que trata do Programa de Prevenção de Riscos Ambientais (PPRA), o empregador deve elaborar um cronograma definindo metas e prioridades para a prevenção de riscos no ambiente laboral.

Diante do exposto, é importante que os profissionais de Segurança no Trabalho e de Saúde do Trabalhador, componentes do Serviço Especializado em Engenharia de Segurança e em Medicina do Trabalho, reúnam esforços que viabilizem a adoção e implementação de medidas preventivas de segurança e de saúde, evitando a ocorrência de acidentes de trabalho e de doenças relacionadas ao trabalho. As falas abaixo revelam a percepção dos entrevistados em relação ao tema: (...) as medidas de biossegurança pra mim significam ficar, como o próprio nome diz, em segurança (...) ( $\left.E_{2}\right) ;($...) é a segurança, tanto do profissional quanto do paciente (...). ( $\left.E_{6}\right)$.

A legislação obriga os empregadores e instituições a admitirem trabalhadores como empregados, implantar medidas que visem à preservação da saúde e da integridade deles através da antecipação, reconhecimento e avaliação e ao conseqüente controle da ocorrência de riscos ambientais existentes, ou que venham a existir no ambiente de trabalho ${ }^{6}$.

A instituição deverá também manter, em local de fácil acesso, o mapa de riscos para que os trabalhadores possam ter informação atualizada acerca da distribuição dos riscos ambientais, contendo a identificação teórica dos agentes biológicos mais prováveis e a avaliação do local de trabalho e do trabalhador exposto ${ }^{6}$.

As categorias apresentadas e discutidas neste capítulo comprovam o pouco conhecimento, e até mesmo um certo desinteresse por parte de alguns profissionais, em relação à necessidade de observar rigorosamente as medidas de biossegurança preconizadas pela legislação vigente. É uma situação que precisa ser reavaliada pelos próprios profissionais para que garantam melhores condições ambientais de trabalho.

\section{CONSIDERAÇÕES FINAIS}

0 fato de poucas vezes a equipe de enfermagem da UTI (cenário do estudo) ter aludido à Engenharia de Segurança do Trabalho no que diz respeito à informação sobre o uso de EPIs, deixa entrever a necessidade de maior integração entre estas equipes com o objetivo de possibilitar e/ou ampliar as discussões acerca das medidas de biossegurança, bem como do uso e dos aspectos ergonômicos destes equipamentos de segurança.

A lavagem das mãos ocorreu com freqüência, por ter sido sempre percebida como uma das medidas mais elementares de proteção ao cliente, mais até do que ao profissional. $\mathrm{Na}$ realidade, 0 ato de lavar as mãos tem de ser observado rigorosamente, mas não deve impedir o uso das luvas quando se tornarem indispensáveis.

Quanto ao coletor de descarte de material perfurocortante, foi possível constatar o correto procedimento da equipe de enfermagem em relação a este tipo de material, posto que todos observaram rigorosamente as normas de biossegurança. Esta é uma questão que deve ser permanentemente abordada em cursos de educação permanente sobre saúde e segurança no trabalho, considerando as situações de estresse que permeiam as características laborais de uma UTI, que podem aumentar a probabilidade de ocorrência de risco de acidentes de trabalho.

Um aspecto que não pode ser descurado é o fato de que esta equipe deve ser objeto de permanente atenção do Setor de Saúde do Trabalhador, visando à vacinação contra a hepatite $B$, a prevenção contra o vírus HIV, o controle da tuberculose e a promoção à saúde através de ações contínuas junto aos seus integrantes.

Deve ser ressaltada a necessidade de adoção de medidas voltadas para a educação permanente da equipe de enfermagem no que se refere às normas de biossegurança. Para tanto, a Instituição deve proporcionar aulas, cursos, seminários, palestras e workshops com o objetivo de que todos compreendam a importância da adoção e implementação dessas medidas na UTI, pois as mesmas visam também à proteção e à segurança do cliente e a de outros profissionais que exercem atividades naquele contexto laboral.

Considerando que a percepção deve levar em consideração não apenas os sentidos, mas também a captação de conhecimento como promoção da coordenação da conduta, pode-se concluir que a adoção e a implementação das medidas de biossegurança na UTI não foram suficientemente profundas, devido à desinformação, à pouca discussão sobre os riscos residuais e à visão acerca destas medidas, que se restringem basicamente à utilização dos EPIs.

Como mencionado anteriormente, as ações de promoção e prevenção em segurança no trabalho são da competência do Setor de Engenharia e Segurança no Trabalho; porém, o enfermeiro, na qualidade de educador e de líder da equipe de enfermagem, deve contribuir para melhorar a percepção de seus pares acerca das medidas de biossegurança em UTI.

Há que se considerar também que as normas de biossegurança devem incluir a implementação das 'boas práticas', possibilitando alcançar um ambiente laboral sem riscos ocupacionais. Ademais, o Enfermeiro do Trabalho deve considerar-se um membro efetivo da Comissão Interna de Prevenção de Acidentes de Trabalho (CIPA) e, assim, cumprindo esse papel, comparecer às reuniões desta Comissão, visando discutir com os profissionais de segurança no trabalho e com os representantes dos trabalhadores os diversos aspectos das condições laborais existentes na UTI para evitar e controlar a ocorrência de riscos ocupacionais e acidentes de trabalho neste setor hospitalar. Deve-se ressaltar a importância do papel que desempenham, respectivamente, a Comissão de Controle de Infecção Hospitalar e o Setor de Saúde e Segurança no Trabalho, com o objetivo de trocarem informações a respeito das condições ambientais e dos trabalhadores de enfermagem. 


\section{Referências}

1. Ishide VM, Benatti MC, Costa NM. Ocorrência de acidente de trabalho em uma unidade de terapia intensiva. Rev. Latino-am Enfermagem. 2004 mar/abr; 38 (4): 406-14.

2. Kirchhof ALC, Capellari C. Descrição das Comunicações de Acidentes de Trabalho Registradas no Instituto Nacional de Seguridade Social de Santa Maria, RS, no Ano de 2000. Rev Gaúcha Enferm 2004 ago; 25 (2): 194-201.

3. Bardin L. Análise de Conteúdo. Lisboa (Portugal): Ed 70; 1979.

4. Mendonça AP, Fernandes MSC, Azevedo JMR, Silveira WCR, Souza ACSC. Lavagem das Mãos: adesão dos profissionais de Saúde em uma Unidade de Terapia Intensiva Neonatal. Acta Sci Health Sci 2003 jul/ ago; 25 (2): 147-53.

5. Mastroeni MF. Biossegurança aplicada a laboratórios e serviços de saúde. São Paulo (SP): Atheneu; 2004.

6. Ministério do Trabalho e Emprego (BR). Normas regulamentadoras. [on line] $2007 \mathrm{abr}$ [aprox. 8 telas]. Disponível em http://www.mte.gov.br.

7. Souza M. Controle de riscos nos serviços de saúde. Acta Paul Enferm 2000 ago; 13 [número especial]: parte 1.

8. Tipple AFV, Pereira MS, Hayashida M, Morlya TM, Souza ACS. 0 ensino do controle de infecção: um ensaio teórico-prático. Revista Latino-am Enfermagem. 2003 mar/abr; 11(2): 245-50.

9. Lacerda RA. Exposição ocupacional ao sangue e a outras substâncias orgânicas de paciente em unidades de centro cirúrgico de hospitais do Brasil [tese de livre docência].São Paulo (SP): Escola de Enfermagem de São Paulo/USP; 2000.

10. Spindola T. Prevenindo Acidentes com pérfuro-cortantes na área hospitalar. Rev Enferm UERJ 1999 jan/jun; 7 (1): 54-60.
11. Secco 10, Robazzi MLCC. Acidentes de trabalho e riscos ocupacionais no dia-a-dia do trabalhador hospitalar: desafio para a saúde do trabalhador. Revista Espaço para a Saúde. [on line] 2002 dez; [citado 12 set 2005]; 4 (1): [aprox 2 telas]. Disponível em www.revistaespaçoparaasaude.com.br.

12. Penteado MS. Biossegurança para agentes biológicos na prática assistencial: um estudo em hospitais da região de Itabuna -BA [tese de doutorado]. São Paulo (SP): Faculdade de Saúde Publica/USP; 2003.

13. Ennes LD. 0 uso, o desuso ou uso inadequado dos equipamentos de proteção individual pela equipe de enfermagem na prevenção dos riscos com material biológico [dissertação de mestrado]. Rio de Janeiro (RJ): Escola de Enfermagem Anna Nery/ UFRJ; 2002.

14. Mattos TMC. Riscos biológicos a saúde do trabalhador de enfermagem em Unidade de Terapia Intensiva [dissertação de mestrado]. Rio de Janeiro (RJ): Escola de Enfermagem Anna Nery/ UFRJ; 2000.

15. Teixeira P, Valle S,organizadores. Biossegurança: uma abordagem multidisciplinar. Rio de Janeiro (RJ): FIOCRUZ; 1996.

\section{Sobre as Autoras}

\section{Chistina Feitoza Correa}

Enfermeira, Mestre em Enfermagem pela Escola de Enfermagem Anna Nery/UFRJ

\section{Marilurde Donato}

Enfermeira, Doutora em Enfermagem. Professor Adjunto da Escola de Enfermagem Anna Nery. 